\title{
A health impact assessment of the Liverpool Hospital redevelopment
}

\section{Michelle L. Maxwell}

Population Health, Sydney South West Area Health Service

Email: michelle.maxwell@sswahs.nsw.gov.au

\begin{abstract}
This case study describes the process and results of a prospective health impact assessment that was conducted on a major hospital redevelopment in NSW. Undertaking the health impact assessment has raised awareness of the potential intended and unintended consequences of redevelopment in relation to health. It has also enhanced the capacity and commitment for health impact assessment within the Area Health Service.
\end{abstract}

Liverpool Hospital is the major tertiary referral hospital in the south-west region of Sydney and is part of Sydney South West Area Health Service. As a result of an increased demand for services, together with a rapidly expanding regional population, the need for additional health care beds, ambulatory care areas and supporting infrastructure has been identified. In 2006, the NSW Government announced the allocation of approximately AU\$390 million to commence the redevelopment of Liverpool Hospital to meet this need.

Health impact assessments (HIAs) have been conducted on several proposed major developments and plans, including health service redevelopments. ${ }^{1,2}$ The redevelopment of the hospital provided an opportunity to conduct a health-focussed impact assessment and to consider the potential consequences of the redevelopment on the health of different population groups.

\section{Methods}

A Steering Committee was established in July 2006 to conduct a prospective intermediate HIA on the redevelopment of Liverpool Hospital. The Steering Committee included Sydney South West Area Health Service representatives from each of Population Health, Planning, Capital Works and the Liverpool Hospital, and also from the University of New South Wales' Centre for Health Equity Training, Research \& Evaluation (CHETRE) and the Redevelopment Project Team. The project was also accepted as a developmental HIA site as part of the NSW Health HIA Project. This project used the structured and step-wise process of HIA described in the literature. ${ }^{3}$ As a result of the screening step of the HIA, the Steering Committee decided to focus the HIA on the construction phase of the redevelopment. This decision was supported by a brief review of the literature and the experiences of other hospital redevelopments where construction was a major issue in terms of impact on health.

The aim of the HIA was to identify the potential positive and negative health impacts of the construction phase. The outcome of the HIA was to develop recommendations for the committee driving the development - the Executive User Group - regarding improvements to health and wellbeing.

In determining the scope for the project, it was decided to conduct the HIA immediately, as the start of the construction phase was scheduled for late 2006 to early 2007. In keeping with this type of HIA, the methods chosen for the identification of impacts were: staff and community consultations, development of a population profile and a literature review. These methods were consistent with the types of evidence for HIA as described by the London Health Observatory. ${ }^{4}$

During the scoping phase, the Steering Committee also decided that the HIA would focus on four key issues for the identification of health impacts. This decision was again based on the available evidence and the prior experiences of other hospital redevelopments. The issues were:

(1) Health and wellbeing of staff and the community

(2) Community and patient safety (non-traffic related)

(3) Increased traffic in area (general and construction traffic) and

(4) Reduced parking for staff, patients and visitors.

To undertake the assessment of impacts, the Steering Committee developed an assessment matrix that included the health impacts, the source of information, affected groups, numbers affected and the consequences and likelihood of the health impact. Consequences and likelihood were assessed using a process similar to the Severity Assessment Code used in conjunction with the NSW Health Incident Management Policy Directive. ${ }^{5}$ The matrix also included a section on the possible actions or recommendations regarding that impact. The assessment 
matrix was completed by a smaller working party and provided to the Steering Committee for endorsement.

\section{Results}

The Steering Committee used the matrix to prioritise the potential health impacts for the recommendations. Reduced parking was determined as the issue with the highest priority, followed by health and wellbeing of staff, community and patient safety and then increased traffic in the area. Within each of these issues, recommendations were ranked in priority order. For example, recommendations for reduced parking were:

- Develop, implement and evaluate a plan to promote the use of active transport for staff

- Review and explore opportunities to maximise the use of current parking spaces

- Explore and report on the feasibility of a Park-andRide system for staff in peak hours

- Initiate the development and implementation of a disability access plan for the construction phase of the redevelopment.

In determining the recommendations, the Steering Committee also acknowledged existing strategies that were in place to reduce potential negative health impacts and to enhance potential positive health impacts during the construction. These existing strategies included:

- An asbestos removal strategy

- The construction of a new access road adjacent to and crossing over the railway line

- The establishment of a Redevelopment Transition Manager's position to facilitate communication

- Various requirements within the Managing Contractor's contract that address health and well being, for example effective safety barriers

- An improved hospital for staff and the local community.

It was also acknowledged that the implementation of the recommendations would occur at different times throughout the construction process, for example, some recommendations such as negotiations with contractors would occur early in the construction phase and others might not be needed until construction was well underway.

A proposed monitoring and evaluation table was developed to determine the impacts of the HIA and progress with the recommendations. The committee highlighted that allocation of resources for the monitoring and evaluation of the HIA over a period of approximately five to eight years - the construction phase of the project - would be necessary. The recommendations were presented to the Executive User Group in March 2007 which accepted the recommendations. The General Manager, Liverpool Hospital, agreed to undertake monitoring and evaluation and report quarterly on progress.

Process evaluation to date has shown that the following elements were crucial to the success of the HIA:

- support and advice from the NSW HIA Project

- the diverse and expert membership of the Steering Committee

- the early definition of the scope of the project

- a project team to coordinate tasks and provide information for decision-making

- engaging stakeholders

- an executive sponsor from the Executive User Group.

\section{Conclusion}

We found that the HIA provided evidence to support the recommendations, raised awareness of possible inequity for disadvantaged groups during the construction phase and strengthened the consultation and communication process for the redevelopment. Undertaking this HIA has developed capacity and enhanced commitment within Sydney South West Area Health Service to conduct future HIAs.

\section{References}

1. Bendel N, Owen-Smith V. A prospective health impact review of the redevelopment of Central Manchester Hospitals. Environ Impact Assess Rev 2005; 25(7-8): 783-90. doi:10.1016/j.eiar.2005.07.009

2. Douglas CH, Higgins A, Dabbs C, Walbank M. Health impact assessment for the sustainable futures of Salford. J Epidemiol Community Health 2004; 58(8): 642-8. doi:10.1136/jech.2003.010397

3. Simpson S, Harris E, Harris-Roxas B. Health impact assessment: an introduction to the what, why and how. Health Promot J Aust 2004; 15(2): 150-5.

4. Mindell J, Biddulph JP, Boaz A, Boltong A, Curtis S, Joffe M, et al. A guide to reviewing evidence for use in Health Impact Assessment. London: London Health Observatory, 2006.

5. NSW Health. Incident Management Policy Directive. Sydney, 24 July 2007. Available from http://www.health.nsw.gov.au/ policies/pd/2007/pdf/PD2007_061.pdf. 